\title{
EDUCAÇÃO MATEMÁTICA E JOGOS DE LINGUAGEM NA ESCOLA: REVERBERAÇÕES ${ }^{1}$
}

Leonidas Roberto Taschetto ${ }^{2}$

Claudia Glavam Duarte ${ }^{3}$

\begin{abstract}
Resumo
O presente texto busca, num primeiro momento, pensar sobre proposições que têm sido colocadas à Educação Matemática, interrogando a pretensão de universalidade da matemática acadêmica para, em um momento posterior, analisar uma das implicações para a Educação Matemática Escolar. De forma específica, desde Wittgenstein,na segunda parte do texto, problematizamos a verdade que se propagou e se enraizou no discurso educacional ao afirmar a necessidade de se trabalhar, a partir da realidade do aluno, em sala de aula a fim de se atribuir significado à matemática escolar.Sustentamosa impossibilidade de tal empreendimento, argumentando que os jogos de linguagem da matemática escolar e aqueles que constituem as práticas sociais, apesar de guardarem semelhanças de família entre si, são distintos e a "passagem" de um jogo de linguagem pertencente a uma forma de vida para a outra, não garantiria a permanência do significado. Antes sugere sua transformação.
\end{abstract}

Palavras-chave: Educação Matemática Escolar; Realidade do Aluno; Racionalidade; Linguagem

1PARA INÍCIO DE CONVERSA...

\footnotetext{
${ }^{1}$ Este artigo é original em língua portuguesa, conquanto uma versão preliminar foi publicada em 2014, em língua inglesa, na InternationalJournal four Research in MathematicsEducation.

2 Pesquisador CNPq. Doutor em Educação pela UFRGS, com período doutoral na Université de Paris VIII. Professor Adjunto no Programa de Pós-graduação em Educação - UNILASALLE, Linha de Pesquisa Formação de Professores, Teorias e Práticas Educativas. Endereço: Avenida Cristóvão Colombo, 139, 208, CEP 90560003. Endereço eletrônico: leontaschetto@yahoo.com.br

${ }^{3}$ Pesquisadora CNPq. Doutora em Educação pela UNISINOS. Professora Adjunta. Coordenadora do Curso de Licenciatura em Educação do Campo: Ciências da Natureza da UFRGS, Campus Litoral Norte. Endereço: Travessa Sapiranga 1275, Centro, Tramandaí-RS. Endereço eletrônico: claudiaglavam@ @otmail.com
} 
Guardadas as divergências e críticas dirigidasà obra de Ludwig Wittgenstein pelo filósofo francêsGilles Deleuze, iniciamos este texto lembrando que, em 1979, Deleuze escreveu um pequeno texto cujo título, bastante promissor e provocativo,indagava: “[...] em que a filosofia pode servir a matemáticos, ou mesmo a músicos: mesmo e, sobretudo, quando ela não fala de música ou de matemática?” (DELEUZE, 2002, p. 225). Movido pelo intuito dequestionar o modelo pedagógico imposto pelas normas do Ministério de Educação ao qual Vincennes não se opunha, masresistira, Deleuze, de certa forma, sinalizava a necessidade de uma filosofia pragmática que propiciasse aos alunos uma participação mais efetiva nas aulas, no sentido de possibilitar intervençõesem função de suas necessidades específicas, fossem eles matemáticos ou músicos. Para Gilles Deleuze,“[...] jogar no interior de cada disciplina ressonâncias entre níveis e domínios de exterioridade" (Ibidem, p.226), é mais do que uma mera ação recomendável ou necessária, trata-se de um movimento extremamente saudável e produtivo que não somente evitaria proposições universais, mas igualmente se tornaria mais problemático permanecer em um terreno cercado, autossuficiente, portanto confortável, seguro, garantido, consequentemente evitando a permanência nos limites de uma ciência régia. Agindo assim, Deleuze acaba se posicionando desde um lugar que evitao modus operandi da tradicional filosofia contemplativa, transcendental, que teria força somente em si mesma, devendonos forçar a pensar, antes de tudo sobre a potência advinda de discussões que abarcam em seu bojo, a exterioridade e, neste caso, pensamos a filosofia em relação à Educação Matemática, para perguntarmos se“[...] isso funciona, e como é que funciona?” (DELEUZE, 2000, p. 16).

Acreditamos que a Educação Matemática tem sido potencializada por essas discussões visto que vem se constituindo como um campo que tem abrigado ultimamente, uma multiplicidade de perspectivas teóricas e uma pluralidade de objetos de análises resultantes das contribuições de pesquisadores interessados em problematizar o conhecimento matemático e suas implicações educacionais. A amplitude desse debate envolvendo essas diferentes abordagens e perspectivas, tem provocado importantes ressignificações no campo da Educação Matemática e isso nos parece ter sido possível em decorrência da ousadia movida pela vontade de saber de alguns pesquisadores que têm se lançado na aventura de buscar em territórios externos à Matemática - filosóficos, estéticos, antropológicos, sociológicos, entre outros - as ferramentas teóricas e conceituais que potencializam o 
pensamento fazendo, numa apologia à Nietzsche (2001, p.313), a Educação Matemática dançar.

É no sentido de potência, de funcionamento e de fazer a Educação Matemática dançar que nos apropriamos da obra de Wittgenstein, mais especificamente as proposições presentes no seu livro Investigações Filosóficas (2004). Tal empreitada torna-se possível, pois, segundo Richard Rorty (1988, p.286), existem diferenças significativas entre o que ele denominou de filósofos sistemáticos e filósofos edificantes. Segundo este autor:

\begin{abstract}
Os grandes filósofos sistemáticos são construtivos e oferecem argumentos. Os grandes filósofos edificantes são reativos e oferecem sátiras, paródias, aforismos. Eles são intencionalmente periféricos. Os grandes filósofos sistemáticos, como os grandes cientistas, constroem para a eternidade. Os grandes filósofos edificantes destroem para o bem de sua geração. Os filósofos sistemáticos querem colocar o seu tema no caminho seguro de uma Ciência. Os filósofos edificantes querem manter o espaço aberto para a sensação de admiração que os poetas podem por vezes causar admiração por haver algo de novo debaixo do sol, algo que não é uma representação exata do que já estava ali, algo que (pelo menos no momento) não pode ser explicado e que mal pode ser descrito. (RORTY, 1988, p. 286)
\end{abstract}

São os espaços abertos, os fluxos e as correntes de ar presentes na obra de Wittgenstein que nos permitem problematizar o campo da Educação Matemática para, quem sabe, levá-lo ao campo do impensável até então. No entanto, nosso esforço é precedido por vários trabalhos que, mesmo abarcando uma multiplicidade teórica, tem utilizado ferramentas deste filósofo para alicerçar suas investigações. Dentre estes destacamos Knijniketall (2012),Wanderer (2007), Villela (2007), Giongo (2008) e Duarte (2003; 2009).É na esteira desses trabalhos que nosso texto se insere e, para facilitar a leitura,dividimos nosso texto em duas partes. A primeira parte refere-seà problematização que as ferramentas wittgensteinianas nos permitiram realizar sobre o caráter universal pretendido pelo conhecimento matemático. Tal questionamento foi problematizado por vários pesquisadores, como referenciado acima, entretanto pensamos não ser possível, ou pelo menos limitado, falar de Wittgenstein sem ponderar suas contribuições para o esfacelamento de qualquer pretensão de universalidade do conhecimento matemático. A segunda parte do textorecebe uma maior ênfase por tratar-se de resultados de uma pesquisa de Doutorado em Educação (Duarte, 2009), refere-se às implicações pedagógicas e políticasda obra do filósofo austríaco para a Educação Matemática.

\title{
1.1Problematizando apretensa racionalidade universal da Matemática Acadêmica
}


As teorizações propostas por Wittgenstein na obra Investigações Filosóficas (2004) têm contribuído, de forma ímpar, para problematizar o caráter universal pretendido pela Matemática Acadêmica e, em efeito, alicerçar as afirmações a respeito da existência de diversas matemáticas.Dessa forma, podemos inferir que

[...] talvez uma das maiores contribuições de Wittgenstein à cultura contemporânea seja exatamente essa "desconstrução" de uma pretensa racionalidade universal, enormemente ancorada na ideia de categorias, que é não apenas idealista, mais arrogantemente etnocêntrica. (CONDÉ, 2004, p. 139).

Esta importante contribuição foi possibilitada pelo entendimento de racionalidade apontada por este filósofo, ao se afastar das tentações sedutoras pela busca de fundamentação última proveniente tanto de posturas essencialistas, através da busca por uma essência lógica (idealista), quanto de posturas que buscam a positividade dos fatos (positivista). Wittgenstein questiona, dessa forma, a racionalidade como o resultado de um modelo representacional da linguagem - que propunha um isomorfismo entre linguagem e mundo. De forma contrária, suas teorizações privilegiam a interação ao invés da representação, ou seja, a racionalidade para este filósofo emerge da gramática, das regras presentes nas interações dos jogos de linguagem, das práticas sociais cotidianas presentes em uma dada forma de vida. Como existem diferentes formas de vida, com diferentes jogos de linguagem, é possível inferir que a existência de diferentes gramáticas possibilitam a construção de diferentes racionalidades.

A expressão formas de vida utilizada pelo filósofo, busca evidenciar o “entrelaçamento entre cultura, visão de mundo e linguagem” (GLOCK, 1998, p. 173). Segundo Quartieri (2012), "não se poderia dizer que existe uma única forma de vida, mas diferentes formas de vida com características de diferentes culturas e épocas” (Ibidem, p. 28). Ou seja, para Wittgenstein existiriam diferentes formas de vida em que diferentes jogos de linguagem seriam utilizados conforme o contexto em que estão inseridos. Nesta mesma linha de argumentação, Glock (1998), afirma que "uma forma de vida é uma formação cultural ou social, a totalidade das atividades comunitárias em que estão imersos os nossos jogos de linguagem" (Ibidem, p. 174).

De forma geral, a filosofia wittgensteiniana da última fase, desestabiliza a compreensão da linguagem enquanto representação do mundo, ou seja, implica em um profundo questionamento e uma crítica ao paradigma da representação, seja ele proveniente 
de uma concepção metafísica ou empirista. Dito de outra forma, para este filósofo, aquilo que conhecemos e damos significados, não está no objeto em si, fruto de uma essência, intenção esta do idealismo, nem na positividade dos fatos, justificativa do empirismo. Nesse sentido, Wittgenstein se afasta do idealismo por não crer na essência do significado e, por outro lado, também do empirismo por não acreditar na existência da objetividade dos fatos ou do objeto.

Para este filósofo, o significado e, por conseguinte o conhecimento, se dá no uso que fazemos da linguagem em uma dada forma de vida, ou seja,

[...] não é mais relevante, para a compreensão do significado, a determinação lógica e definitiva de unidades mínimas formais, sintáticas ou semânticas, nem a postulação de tais unidades como sendo os fundamentos do significado. Trata-se agora, de buscar unidades, de outra ordem, ou melhor, que serão caracterizadas segundo outros critérios. Os novos critérios, todavia serão de natureza distinta dos anteriores, uma vez que não mais será possível, por meio deles, detectar exata e definitivamente as unidades do significado. Os novos critérios serão fornecidos pelo uso que fazemos da linguagem, nos mais diversos jogos, isto é, nas mais diferentes formas de vida. (MORENO, 1995, p. 56).

Nesta perspectiva, sua concepção de linguagem afirma não existir

[...] a linguagem, mas simplesmente linguagens, isto é, uma variedade imensa de usos, uma pluralidade de funções ou papéis que poderíamos compreender como jogos de linguagem. Entretanto, como também não há uma função única ou privilegiada que possa determinar algum tipo de essência da linguagem, não há também algo que possa ser a essência dos jogos de linguagem. (WITTGENSTEIN apud CONDÉ, 1998, p. 86).

Wittgenstein, ao afirmar a inexistência de uma essência da linguagem, admite que nenhuma linguagem pode pretender-se universal. Existem linguagens e lógicas particulares, e estas são fruto do contexto onde estão inseridas. Nessa perspectiva, a obra de Wittgenstein fornece a possibilidade para pesquisadores, especialmente àqueles vinculados aEtnomatemática, ${ }^{4}$ questionarem a pretensão de universalidade da linguagem da Matemática acadêmica. Assim:

A Matemática Acadêmica, a Matemática Escolar, as Matemáticas Camponesas, as Matemáticas Indígenas, em suma, as Matemáticas geradas por grupos culturais específicos podem ser entendidos como conjuntos de jogos de linguagem engendrados em diferentes formas de vida, agregando critérios de racionalidade

\footnotetext{
4 "Entendemos a Etnomatemática como uma caixa de ferramentas que nos permite [...] estudar os discursos eurocêntricos que instituem as matemáticas acadêmica e escolar; analisar os efeitos de verdade produzidos pelos discursos das matemáticas acadêmica e escolar; discutir questões da diferença na educação matemática, considerando a centralidade da cultura e as relações de poder que a instituem; e examinar os jogos de linguagem que constituem cada uma das diferentes matemáticas, analisando suas semelhanças de família" (KNIJNIK, 2006, p. 120).
} 
específicos. Porém, esses diferentes jogos não possuem uma essência invariável que os mantenha completamente incomunicáveis uns dos outros, nem uma propriedade comum a todos eles, mas algumas analogias ou parentescos- o que Wittgenstein denomina de semelhanças de família. (KNIJNIKet ali, 2012, p.31).

Para este filósofo, existem jogos de linguagem, e estes estão articulados com as possibilidades de seus usos, nas formas de vida. Tal condição inviabiliza a possibilidade de afirmação de uma linguagem universal, ideal. Além disso, na perspectiva do autor, a função da linguagem não é denotativa, isto é, ela não é representativa das coisas que cercam o mundo e sim atributiva, não existindo, portanto, correspondência biunívoca entre as palavras e as coisas. Dessa maneira, as "verdades" não são encontradas através da razão, mas inventadas por ela. Assim sendo, é através dos usos da linguagem que são atribuídos sentidos às atividades, aos objetos e aos acontecimentos e não apenas aspectos alcançados por meio da percepção. Em consequência disso, aquilo que chamamos de "realidade" é construído na e através da pragmática da linguagem, ou seja, “[...] aquilo que para os homens parece assim, é o seu critério para o que é assim” (WITTGENSTEIN apud MORENO, 1995, p. 33).

Nessa perspectiva, todos os jogos de linguagem estão corretos desde que os critérios para esta validação tenham sentido dentro de uma determinada forma de vida. Isto implica que, "[...] Naturalmente, formas de vida diversas estabelecem[çam] práticas diferenciadas, assim também, gramáticas diferentes e, consequentemente, inteligibilidades diferentes" (CONDÉ, 2004, p.110). Nesse sentido, não se pode falar de inteligibilidade do mundo, mas de inteligibilidades possíveis.No entanto,

O ideal está fixado em nossos pensamentos de modo irremovível. Você pode sair dele. Você tem que voltar sempre de novo. Não existe um lá fora; lá fora falta o ar vital. - Donde vem isto? A ideia está colocada, por assim dizer, como óculos sobre o nosso nariz, e o que vemos, vemo-lo através deles. Não nos ocorre tirá-los. (WITTGENSTEIN, 1991, p. 69).

É com os óculos da Matemática acadêmica que tem sido construído o suposto "ideal”. No entanto, é preciso considerar a Matemática acadêmica como uma lente, uma possibilidade, uma linguagem que não é o reflexo do mundo, mas que, ao "dizer sobre o mundo", acaba por construí-lo e o faz de uma maneira bastante peculiar.

Ao longo da história da humanidade, distintos povos geraram seus modos próprios de contar, medir, registrar o tempo e entender os fenômenos naturais. Esses modos particulares 
de compreender o mundo, através de uma perspectiva matemática, fazem-se presentes em diferentes práticas sociais.

Ubiratan D'Ambrósio (2005, p.6) afirma que, desde o final do século XV e ao longo do século XVI, o estabelecimento de regimes coloniais, em escala mundial, determinou que as diferentes modalidades locais de produção e comercialização se adequassem ao modelo europeu. Assim, as particularidades intelectuais dos povos conquistados foram amplamente abandonadas. Desse modo, formas específicas de mensurar, quantificar, linguagens e outras expressões culturais foram silenciadas.

A questão que se coloca, frente à existência de outros tipos de validação, de outras lógicas, é porque algumas são legitimadas e outras não, porque algumas são merecedoras de espaços dentro do currículo escolar e outras não.

Vários pesquisadores e estudiosos da Etnomatemática têm buscado compreender e validar estas "outras" lógicas presentes nas mais diversificadas culturas. Monteiro (2002) relata uma experiência que viveu junto a um grupo do Assentamento Rural de Sumaré. Naquele local, a autora descreve seu encontro com Zé do Pito, plantador de tomates, que além de dedicar-se aos afazeres provenientes deste ofício, era responsável pela divisão do valor da conta de luz do assentamento entre os usuários. Os procedimentos do trabalhador rural, para efetuar os cálculos, resumiam-se em dividir a taxa básica entre os que usaram a luz e o valor restante dividir conforme as condições de cada família. Sua divisão era proporcional, porém os critérios para estabelecer tal proporcionalidade estavam articulados a partir de "relações de solidariedade e não de capital” (MONTEIRO, 2002 p. 104). Segundo a autora, tal situação

\footnotetext{
[...] recheada de vida, não fala apenas de uma divisão, fala de critérios de divisão, fala da razão pela qual devemos dividir e dos valores envolvidos nessa prática. $\mathrm{O}$ cálculo é algo secundário. O senhor Zé do Pito nunca estudou e sabia fazer cálculos, como ele dizia, de cabeça ou com a calculadora que seus filhos the ensinaram a manusear. (MONTEIRO, 2002, p. 105).
}

Experiência também diferenciada no que diz respeito a outras formas de matematizar, ou em uma linguagem wittgensteiniana, outros jogos de linguagem, foi vivenciada por Mariana Kawall Ferreira, como professora de Português e Matemática na escola do Diauarum no parque indígena do Xingu. Ao propor para a turma à qual lecionava, o problema: "Ontem à noite peguei 10 peixes. Dei 3 para meu irmão. Quantos peixes tenho agora?” (FERREIRA, 2002, p. 56), obteve como resposta 13 peixes. Ao analisarmos, com as lentes da Matemática acadêmica, o valor encontrado, poderíamos pensar que tal resultado foi, no mínimo, 
equivocado ou que havia uma "incapacidade cognitiva" por parte deste aluno, já que a operação aritmética que responderia "corretamente" a este problema seria, obviamente, a subtração que produziria como resultado sete peixes. No entanto a justificativa para a escolha da operação adição é surpreendente. De acordo com a explicação do aluno:

Fiquei com 13 peixes porque, quando eu dou alguma coisa para meu irmão, ele me paga de volta em dobro. Então 3 mais 3 é igual a 6 (o que o irmão lhe pagaria de volta); 10 mais 6 é igual a 16; e 16 menos 3 é igual a 13 (número total de peixes menos os 3 que Tarinu deu ao irmão). (FERREIRA, 2002, p. 56).

Situações como essas indicam que impor uma determinada racionalidade, através da Matemática acadêmica, significa muito mais do que dar primazia a um modo de pensar, a uma gramática específica: significa a possibilidade de destruir os valores e significados que acompanham a racionalidade de outras culturas. O que significaria impor para tais comunidades - do Assentamento de Sumaré ou do Parque Xingu-critérios para validação de resultados baseados somente naqueles presentes na Matemática escolar? Tomaz Tadeu da Silva (1998, p. 194), ao assinalar a importância de “[...] ver o currículo não apenas como sendo constituído de 'fazer coisas', mas também vê-lo como "fazendo coisas às pessoas", aponta-nos os perigos da imposição de uma única racionalidade. Nesse sentido, as ferramentas wittgensteinianas têm nos ajudado a problematizar a existência de uma única matemática que seria resultado de uma única e "verdadeira" racionalidade. Porém, como afirmamos anteriormente, este texto pretende adensar a discussão sobre algumas proposições feitas para o ensino da Matemática à luz das teorizações de Wittgenstein.

\subsection{Problematizando umas das verdades do Discurso da Matemática escolar:trabalhar com a realidade do aluno permite dar significado à matemática escolar}

Além do esfacelamento da pretensão de universalidade do conhecimento matemático, a obra de Wittgenstein nos oferece ferramentas para problematizarmos as propostas pedagógicas que afirmam a necessidade de trabalharmos com a realidade do aluno, a fim de darmos significado à matemática escolar. Parece-nos que esta necessidade se legitimaria pelo duplo efeito que poderia acarretar: por um lado, tornaria a escola atraente e, por outro, despertaria o interesse do aluno pela aprendizagem da matemática escolar. Seria a tentativa de 
captura do "brilho do real" (LARROSA, 2008), a fim de superar a opacidade e artificialidade dos conteúdos escolares.

Assim, tal prescrição é bastante recorrente no meio educacional sendo sustentada por diferentes perspectivas. Vertentes como a Modelagem Matemática ea Etnomatemática, por exemplo, reforçam muitas vezes a necessidade de articularmos os conhecimentos escolares com a realidade do aluno. No entanto, esta necessidade se estende ao longo dos tempos e extrapola os tempos atuais. Analisando algumas obras de importantes teóricos da Educação Ocidental, percebemos a preocupação em se evitar a clivagem da escola com o mundo real. Assim, expoentes como Wolfgang Ratke e Jan Amos Komenský (Comenius), do século XVII, os escritos de Jean Jacques Rousseau, do século XVIII, reforçam a necessidade pedagógica de atentarmos para o entorno escolar.

Em tudo é necessário seguir a ordem das coisas e se assegurar que os ensinos dos instrumentos não podem ser entendidos sem as coisas. Assim também, devem-se esclarecer as regras, utilizando exemplos e modelos tirados das coisas e, a partir delas, efetuar os ensinamentos. (RATKE, 2008, p. 129) [Grifos nossos].

\begin{abstract}
As palavras, portanto, deverão ser ensinadas e aprendidas sempre em conjunto com as coisas correspondentes [...] E o que são as palavras senão o invólucro e a bainhas das coisas? [...] estamos formando homens, e queremos formá-los no tempo mais curto possível: isso acontecerá se as palavras sempre caminharem pari passu com as coisas, e as coisas com as palavras(COMENIUS, 2006, p.223). [Grifos nossos].
\end{abstract}

Em qualquer estudo que seja, sem a ideia das coisas representadas, os signos representantes não são nada. Todavia, sempre limitamos a criança a esses signos, sem jamais podermos fazê-la compreender nenhuma das coisas que representam. (ROUSSEAU, 2004, p. 123). [Grifos nossos].

Assim, atravessando séculos, a análise, sob diferentes perspectivas, da relação a ser estabelecida entre as "palavras e as coisas" - (realia) ${ }^{5}$ fez-se presente nas discussões de cunho

\footnotetext{
${ }^{5}$ Segundo o Dicionário Etimológico Nova Fronteira da Língua Portuguesa (CUNHA, 1999, p.665), o verbete realidade, na língua portuguesa, remonta ao século XVI. Associado à palavra real, que se refere "ao que existe de fato, verdadeiro, [...] do baixo latim realis, de res rei, coisa". Segundo Hoff e Cardoso (s/d, p.13), a expressão realia está ligada a "[...] (coisas reais): ensino a partir da realidade do aluno. Realia tomou um sentido mais específico, como um conjunto de disciplinas que se ensinava após o ler, escrever, calcular e a doutrina cristã, a partir do terceiro ano, correspondendo à história, geografia e ciências naturais. Por fim, também era considerada uma disciplina metodológica". Lúcio Kreutz (1996), ao fazer um estudo sobre os métodos pedagógicos praticados no início da república nas escolas de imigrantes alemães no Rio Grande do Sul, identificou que a "lição das coisas" sinalizava uma nova postura metodológica na escola da época. Tratava-se, segundo o pesquisador, de uma perspectiva metodológica que buscava superar a lição de palavras. "Todo o processo escolar, de forma especial, o material didático, deveria partir da realidade dos alunos e ajudá-los a integrar-se ativamente em seu contexto social. Um dos termos mais usados para sinalizar essa perspectiva metodológica foi de lições de coisas (realia)" (Ibidem, p. 76) [Grifos do autor]. Assim, fazer uso pedagógico das coisas que
} 
educacional. Do ponto de vista destes autores, para uma aprendizagem ser eficiente, fazia-se necessário estabelecer um "[...] vínculo entre as palavras e as coisas: tudo deve partir do sensível e do sabido", afirmou Comenius (2006, p. 9). Assim, para esses autores, a função representativa da linguagem expressa uma correspondência biunívoca entre mundo e linguagem. Se a relação entre as palavras e as coisas não fosse estabelecida no âmbito educacional, as palavras não passariam de sons vazios, expressões sem significados. O mundo funcionaria, então, como uma base física, imóvel, cuja essência seria expressa pela linguagem. No campo educacional, evitar o esvaziamento dos significados seria um a priori para a aprendizagem. Dessa forma, guardadas as especificidades das formulações de Ratke (2008), Comenius (2006) e Rousseau (2004), a "realidade" sensível ou a apreensão de seus movimentos servem como um aporte fundamental para direcionar o ensino e a aprendizagem do aluno. Assim, é possível inferir a existência de uma preocupação pedagógica, já nos séculos XVII e XVIII, com a desvinculação entre o espaço escolar e seu entorno. Tal preocupação estendeu-se e re/configurou-se no século XX com John Dewey.

Dewey (1959), problematiza uma das caraterísticas que ele considera inerente à instituição escolar: a sua superficialidade. Para ele, tal característica pode impulsioná-la facilmente para o desenvolvimento de práticas pedagógicas "distante[s] e morta[s] abstrata[s] e livresca[s]"'(Ibidem, p. 9). Isso ocorre, de acordo com o autor, porque o nível de complexidade de nossa cultura exige que muito do que se deva aprender esteja vinculado a símbolos abstratos que, por sua condição, estão distanciados da interação com fatos e objetos. Tal "inclinação natural” deve ser cuidadosamente remediada através da capacitação de "modos de ensinar mais fundamentais e eficazes". Conteúdos distanciados da vida real e, por isso, sem utilidade prática, considerados "resíduos inúteis do tempo passado" levavam o professor a perder um tempo precioso, visto que o programa a ser desenvolvido era muito extenso. A busca por uma formalização que ignora as necessidades sociais é uma das críticas da filosofia deweyana voltada à educação.

Assim, a escola, longe de assumir uma postura de imposição, de transmissão direta de conhecimentos, deve entender que sua eficácia está na possibilidade de harmonia com o meio social - e as práticas aí inseridas - em que a criança vive. A advertência é dada pelo filósofo, pois

circundavam a "realidade" do aluno era designado pelo "termo latino realia [que] significa coisas reais, coisas objetivas." (Ibidem, p.81). 
[...] quando as escolas se afastam das condições educacionais eficazes do meio extra-escolar, elas necessariamente substituem um espírito livresco e pseudointelectual a um espírito social. [...] Conservando um indivíduo isolado [das atividades extra-escolares], conseguiremos garantir-lhes a atividade motora e a excitação sensorial: mas não poderemos desse modo fazê-lo compreender a significação das coisas na vida de que faz parte. (DEWEY, 1959, p.42).

Nesse sentido, Dewey afirma a positividade da interlocução entre atividades cotidianas como objeto de experiências, para atividades escolares. Tal positividade ocorre em dois aspectos. Por um lado, permite a visibilidade de conceitos escolares em situações extraescolares, o que lhe imprime significado e, por outro lado, a situação, o contexto oferece um direcionamento para o pensar. Esta interlocução de que fala Dewey, fica potencializada na Educação Matemática visto que:

[...] no caso dos estudos chamados disciplinares ou preponderantemente lógicos, há o perigo de isolar-se a atividade intelectual, das coisas da vida comum. O professor e o estudante tendem, de colaboração, a abrir um abismo entre o pensamento lógico como algo abstrato e remoto, e as exigências particulares e concretas dos acontecimentos diários. O abstrato tende a remontar-se tão alto e a afastar-se tanto da aplicação, que perde toda a relação com o procedimento prático e moral. (DEWEY, 1979, p.68-69).

Nessa perspectiva, a "estratégia metodológica" de aproximar "as atividades matemáticas da realidade" atravessa séculos e se reatualiza. Porém, não deixa de ser objeto de necessidade primeira para as experiências educativas e torna-se prescrição diária ao professor, que deve ensinar os conteúdos matemáticos relacionados harmoniosamente com a "vida real". Assim, a vontade de "realidade", ou seja, a reivindicação pela "intensidade e o brilho do real" (LARROSA, 2008, p.186), a busca pela harmonia e sintonia com a "realidade" é traduzida, entre outras formas, pela necessidade de estabelecer ligações entre a matemática escolar e a "vida real". Seria algo como se a matemática escolar, depois de se afastar do mundo social pelas exigências do formalismo e da abstração que a caracterizam - necessitasse retornar à "vida real", ou seja, realizar-se. Dito de outro modo, injetar "bocados" de "realidade" no cotidiano escolar, aliviaria a suspeita de que os conteúdos desenvolvidos na escola seriam "uma espécie de realidade sem realidade" (LARROSA, 2008, p. 185).

No entanto, o movimento de construção de uma "realidade escolar" com o "brilho do real” é inviabilizado, pois, segundo Larrosa (2008), o real guarda a característica da não intencionalidade: 
As intenções sobre o real, inclusive as melhores intenções, também nos separam do real, também o desrealizam e o desperdiçam, posto que o fabricam de acordo com os nossos objetivos e o convertem em matéria prima de uma transformação, ou de uma modificação possível.(Ibidem, p. 188).

Assim, fabricada de acordo com os objetivos educacionais, a "realidade"é, segundo esse autor, transformada em um "clone de si” (LARROSA, 2008, p. 188), algo como uma paródia da "realidade".

No entanto, achamos pertinente, a partir de ferramentas wittgensteinianas, questionar: Que posições teóricas subsidiariam a afirmação de que trabalhar com a "realidade" do estudante para as aulas de matemática "daria significado" à matemática escolar?

Conforme afirmamos anteriormente, o pensamento do segundo Wittgenstein oferece ferramentas para ensaiar uma resposta para essas indagações. Primeiro, é preciso atentar que tal afirmação poderia nos levar a pensar que os jogos de linguagem que conformam a matemática escolar seriam "vazios" de significado. Em contrapartida, as matemáticas da "realidade", isto é, as não escolares, essas, sim, estariam encharcadas e saturadas de significados, aguardando, "lá fora", para serem transferidas para a forma de vida escolar. Entraria em cena, então, uma "natural" operação de transferência: os significados presentes nas matemáticas não escolares, seriam remetidos para a matemática escolar.

No entanto, na perspectiva wittgensteiniana que assumimos, entendemos que não é possível haver um "esvaziamento/saturação" de significados. Todos os jogos de linguagem sendo práticas sociais - possuem significados dentro da forma de vida que os abriga. Considerada como um conjunto de jogos de linguagem, a matemática escolar apresenta uma gramática específica, conformada por um conjunto de regras. Assim entendida, a matemática escolar não apresenta uma incompletude que é sanada mediante seu contato com a "realidade", pois, segundo o filósofo:

A realidade não é uma propriedade ainda ausente no que se espera e que tem acesso a ela quando nossa expectativa é cumprida. - Tampouco é a realidade como a luz do dia de que as coisas precisam para adquirir cor, quando estão, por assim dizer, sem cor, no escuro. (WITTGENSTEIN, 2003, p. 102).

Ademais, Wittgenstein considera que "as regras da gramática não podem ser justificadas mostrando que sua aplicação faz uma representação concordar com a realidade, pois essa justificativa teria, ela própria, de descrever o que é representado". (WITTGENSTEIN, 2003, p. 141). Mas, se capturados por uma "vontade de realidade", 
fôssemos levados a insistir sobre a possibilidade de transferência de significados dos jogos praticados nas formas de vida não escolares, para os jogos de linguagem da matemática escolar, tal insistência não seria bem sucedida: a "passagem" de uma forma de vida a outra, não garante a permanência do significado: sugere sua transformação, porque "do outro lado" quem "o recebe" é outra forma de vida (VEIGA-NETO, 2004). Dito de outro modo, o significado não possui uma essência que poderia ser abarcada por qualquer uso que se fizesse do enunciado. Nessa mesma perspectiva, Condé (2004) esclarece:

\footnotetext{
Um jogo de linguagem que é plenamente satisfatório dentro de uma determinada situação pode não ser em outra, pois ao surgirem novos elementos as situações mudam, e os usos que então funcionavam podem não mais ser satisfatórios em uma nova situação. (CONDÉ, 2004, p. 89).
}

Assim, os significados produzidos por um jogo de linguagem, que é plenamente satisfatório dentro de uma situação extraescolar, poderiam não funcionar satisfatoriamente quando transferidos para uma situação escolar.

Assim como dito em Knijnik et. al. (2012), existem racionalidades diferentes “[...] operando na Educação Matemática praticada na escola e fora dela: a matemática escolar tem como marca a transcendência e as práticas fora da escola são marcadas pela imanência" (Ibidem, p. 18). Ou seja, as práticas,que fora da escola estão fortemente vinculadas às formas de vida que as pratica, estariam vinculadas ao sujeito. Assim, afirmar que a racionalidade matemática fora do âmbito escolar está entrelaçada com a forma de vida que a sustenta,pressupõe pensarmos as dificuldades de sua inclusão no âmbito escolar. Dito de outra forma, as implicações educacionais advindas da inclusão das práticas sociais de diferentes formas de vida não seriam tão óbvias, pois os saberes aí incorporados estariam sujeitos a transformações nos seus significados, principalmente mediante aos usos dados a eles em outro contexto.

\section{PALAVRAS FINAIS}

Este texto, escrito a partir de uma inserção em territórios da filosofia, teve como objetivo dar visibilidade às implicações da obrade Wittgenstein ao campo da Educação Matemática. De forma geral, ressaltamos as ferramentas teóricas disponibilizadas pelo filósofo austríaco que nos permitem problematizar metanarrativas que parecem configurar-se como inquestionáveis para este campo. Assim, em um primeiro momento, desconfiamos do 
suposto e pretendido caráter de universalidade do conhecimento matemático “[...] capaz de medir e classificar qualquer outra matemática como mais ou menos avançada em função de sua maior ou menor semelhança com aquela que aprendemos nas instituições acadêmicas" (LIZCANO apud KNIJNIK etalli, 2012, p. 2). Poder-se-ia inferir que o caráter de universalidade da matemática estaria vinculado a uma postura transcendental, pois a entenderia como pertencendo ao mundo das ideias. "Nessa perspectiva, o conhecimento estaria aguardando para ser descoberto - Fiat lux - e qualquer cultura, obviamente que em determinado ponto de evolução, teria condições de acessar tal conhecimento" (DUARTE, 2011, p.76). Como afirma Knijniketall. (2012): "O "Segundo" Wittgenstein concebe a linguagem não mais com as marcas da universalidade, perfeição e ordem, como se preexistisse às ações humanas".

O questionamento dessa premissa e de outras verdades "naturalizadas" no campo da Educação Matemática tem sido tensionado a partir da obra de Wittgenstein, especificamente o "último Wittgenstein".

Nessa perspectiva, na segunda parte deste texto, colocamos sob suspeita uma ideia bastante difundida entre aqueles que se ocupam do ensino da matemática de que a "realidade" possibilitaria dar significado aos conteúdos trabalhados em sala de aula, especificamente, aos conteúdos matemáticos. A importância de significar os conceitos escolares a partir de sua aparição na "realidade" teriaum duplo efeito: por um lado, tornaria a escola atraente e, por outro, despertaria o interesse do aluno pela aprendizagem da matemática escolar. Servindonos de ferramentas oriundas da obra do segundo Wittgenstein, problematizamos a possibilidade de tal empreendimento, argumentando que os jogos de linguagem da matemática escolar e aqueles que constituem as práticas sociais, apesar de guardarem semelhanças de família entre si, são distintos e a "passagem" de um jogo de linguagem pertencente a uma forma de vida para a outra, não garantiria a permanência do significado, mas, sugere sua transformação.

Encerramos a escrita deste texto entendendo que outras questões poderiam ser exploradas a partir do pensamento wittgensteiniano. Não tivemos, de modo algum, a pretensão de esgotar a discussão aqui iniciada. De forma contrária, nosso movimento, neste texto, esteve alinhado ao desejo de produzir novos sentidos para as situações vividas, "soltar o ar fresco das outras possibilidades" (TADEU; CORAZZA; ZORDAN, 2004, p.22) e, com 
isso, potencializar diferentes formas de pensamento, que gerem outras possibilidades pedagógicas para a área da Educação, especificamente para a Educação Matemática Escolar.

\title{
MATHEMATICS EDUCATION AND LANGUAGE GAMES IN SCHOOL: REVERBARATIONS
}

\begin{abstract}
At first, this text searches to think about proposals that have been presented for Mathematics Education on questioning the universality claim of academic mathematics and later, to analyze one of the implications for School Mathematics Education. Specifically, since Wittgenstein, in the second part of the text, we question the truth that was spread out and rooted in the educational discourse by stating the need to work from the reality of the student in the classroom in order to give meaning to school math. We sustain the impossibility of this fact by arguing that language games of school mathematics and those which are social practices, although they keep familiarities among them, they are distinct and the "passage" from a language game belonging to a form of life to other would not guarantee the permanence of the meaning. It suggests before its transformation.
\end{abstract}

Keywords: School Mathematics Education; Reality of Student; Rationality; Language

\section{LA ENSEÑANZA MATEMÁTICA EN LA ESCUELA Y LOS JUEGOS DE LENGUAJE: REVERBERACIONES}

\section{Resumen}

Este texto tiene por objeto, en primer lugar, pensar en las propuestas que han sido puestas a la Educación Matemática, cuestionando la pretensión de universalidad de la matemática académica, para, en un momento posterior, analizar una de las implicaciones para la Escuela de Educación Matemática. En concreto, desde Wittgenstein, en la segunda parte del texto, cuestionamos la verdad que se ha extendido y se radicó en el discurso educativo al afirmar la 
TASCHETTO, L.; DUARTE, C.

necesidad de trabajar desde la realidad del estudiante en el aula con el fin de atribuir significado a la matemática. Nosotros sostenemos la imposibilidad de tal compromiso, con el argumento de que los juegos de lenguaje de las matemáticas y aquellos que constituyen las prácticas sociales, aunque mantienen semejanzas familiares entre sí, son distintos y el "paso" de un juego de lenguaje que pertenece a una forma de vida por otro no garantiza la permanencia de significado. Antes sugiere su transformación.

Palabras-clave: Educación; Matemática; Escuela; Realidad del Estudiante; La racionalidad; Lenguaje

\section{REFERÊNCIAS}

COMENIUS, Johann A.Didática Magna. São Paulo: Martins Fontes, 2006.

CONDÉ, Mauro Lúcio L. As teias da razão: Wittgenstein e a crise da racionalidade moderna. Belo Horizonte: Argvmentvm, 2004.

.Wittgenstein linguagem e mundo. São Paulo: Annablume, 1998.

CUNHA, Antônio Geraldo da.Dicionário etimológico Nova Fronteira da língua portuguesa. Rio de Janeiro: Nova Fronteira, 1999.

D’AMBRÓSIO, Ubiratan. Volta ao mundo em 80 matemáticas. Scientific American Brasil, São Paulo, n.11,p.20-23, 2005.

DELEUZE, Gilles. Em quê a filosofia pode servir a matemáticos, ou mesmo a músicos: mesmo e sobretudo quando ela não fala de música ou de matemática. Educação\& Realidade, Porto Alegre: Faculdade de Educação; Universidade Federal do Rio Grande do Sul, v..27, n.2, p. 225-226, jul/dez. 2002.

Conversações. Rio de Janeiro: Editora 34, 2000.

DEWEY, John. Como pensamos. São Paulo: Companhia Editora Nacional, 1979.

. Democracia e educação. São Paulo: Companhia Editora Nacional, 1959.

DUARTE, Claudia G.Etnomatemática, Currículo e Práticas Sociais do "Mundo da Construção Civil”. 2003. 191f. Dissertação (Mestrado em Educação) - Programa de PósGraduação em Educação, Universidade do Vale do Rio dos Sinos, São Leopoldo.

. A "realidade" nas tramas discursivas da educação matemática escolar.2009. 191f. Tese (Doutorado em Educação) - Programa de Pós-Graduação em Educação, Universidade do Vale do Rio dos Sinos, São Leopoldo. 
Produzindo fissuras nas "verdades" da matemática. In: HENNING, P. C. et all (orgs.) Perspectivas de investigação no campo da educação ambiental \& educação em ciências. Rio Grande, RS: FURG, 2011.

FERREIRA, Mariana Kawall L.Idéias matemáticas de povos culturalmente distintos. São Paulo: Global, 2002.

GIONGO, Ieda M. Disciplinamento e resistência dos corpos e dos Saberes: um estudo sobre a educação matemática da Escola estadual técnica agrícola Guaporé. 2008.205f. Tese (Doutorado em Educação) - Programa de Pós-Graduação em Educação, Universidade do Vale do Rio dos Sinos, São Leopoldo.

GLOCK, Hans-Johann.Dicionário Wittgenstein. Tradução de Helena Martins. Rio de Janeiro: Jorge Zahar, 1998.

KNIJNIK, Gelsa; WANDERER, Fernanda.; GIONGO, Ieda M.; DUARTE, Claudia G.Etnomatemática em movimento. Belo Horizonte: Autêntica, 2012.

KNIJNIK, Gelsa. Educação matemática, culturas e conhecimento na luta pela terra. Santa Cruz do Sul: EDUNISC, 2006.

KREUTZ, Lúcio. Representações diferenciadas de lições de coisas no início da República. Estudos Leopoldenses, São Leopoldo - UNISINOS, v. 32, n. 148, 1996, p. 75-86.

LARROSA, Jorge. Desejo de realidade. Experiência e alteridade na investigação educativa. In: BORBA, Siomara; KOHAN, Walter (orgs.). Filosofia, aprendizagem, experiência. Belo Horizonte: Autêntica, 2008.

MONTEIRO, Alexandrina. A etnomatemática em cenários de escolarização: alguns elementos de reflexão. Reflexão e Ação, Santa Cruz do Sul: UNISC, v. 10, n. 1, p. 93-108, jan./jun. 2002.

MORENO, ArleyR.Wittgenstein através das imagens. Campinas: Editora da UNICAMP, 1995.

NIETZSCHE, Friedrich. A gaia ciência. São Paulo: Companhia das Letras, 2001.

QUARTIERI, Marli T.A modelagem matemática na escola básica:a mobilização do interesse do aluno e o privilegiamento da matemática escolar. 2012. 199f. Tese (Doutorado em Educação) - Programa de Pós-Graduação em Educação, Universidade do Vale do Rio dos Sinos, São Leopoldo.

RATKE, Wolfgang. Escritos sobre a nova arte de ensinar de Wolfgang Ratke (1571 - 1635). São Paulo: Autores Associados, 2008.

RORTY, Richard. A filosofia e o espelho da natureza. Lisboa: D.Quixote, 1988.

ROSSEAU, Jean-Jacques.Emílio ou da Educação. São Paulo: Martins Fontes, 2004. 
SILVA, Tomaz T. Currículo e Identidade Social: Territórios Contestados. In: SILVA, Tomaz Tadeu da (Org.). Alienígenas na sala de aula:uma introdução aos estudos culturais em educação. 2. ed. Petrópolis: Vozes, 1998.

SILVA, Tomaz T.; CORAZZA, Sandra; ZORDAN, Paola. Linhas de escrita. Belo Horizonte: Autêntica, 2004.

VEIGA-NETO, Alfredo. Nietzsche e Wittgenstein. In: GALLO, Sílvio; SOUZA, Regina Maria. (org). Educação do preconceito: ensaios sobre poder e resistência. São Paulo: Ed. Alínea, 2004.

VILELA, Denise S.Matemáticas nos usos e jogos de linguagem:ampliando concepções na Educação Matemática. 2007.260f. Tese (Doutorado em Educação) - Universidade Estadual de Campinas, Campinas.

WANDERER, Fernanda. Escola e matemática escolar: mecanismos de regulação sobre sujeitos escolares de uma localidade rural de colonização alemã do Rio Grande do Sul. 2007. 228f.Tese (Doutorado em Programa de Pós Graduação em Educação) - Universidade do Vale do Rio dos Sinos, São Leopoldo.

WITTGENSTEIN, Ludwig. Investigações filosóficas. 3.ed. Petrópolis: Vozes, 2004.

.Gramática filosófica. São Paulo: edições Loyola, 2003.

Investigações filosóficas. Seleção de textos de José Carlos Bruni. 5. ed. São Paulo: Nova Cultural, 1991. (Os pensadores).

Data de recebimento: $24 / 03 / 2015$

Data de aceite: 14/04/2015 